\title{
Correction to: The International Political Economy of Health
}

\author{
Jappe Eckhardt and Kelley Lee
}

Correction to:

Chapter 41: The International Political Economy of Health: T. M. Shaw et al. (eds.), The Palgrave Handbook of Contemporary International Political Economy, Palgrave Handbooks in IPE, https://doi.org/10.1057/978-1-137-45443-0_41

The original version of this chapter was revised.

Jappe Eckhardt's institution is erroneously listed as University of Heslington, which has now been corrected as University of York

The updated original online version for this chapter can be found at https://doi.org/10.1057/978-1-137-45443-0_41 